\title{
APPLICATIONS OF BIBLIOMETRIC ANALYSIS IN MANAGEMENT
}

\author{
Gabriel MĂNESCU ${ }^{a^{*}}$, Ghiță BÂRSAN ${ }^{b}$, Dorel BADEA ${ }^{c}$, Diana-Elena RANF $^{d}$ \\ a, b, c, d Nicolae Bălcescu Land Forces Academy, Sibiu, Romania
}

\begin{abstract}
Scientific manifestations are the main tool through which the results of research are disseminated and the feedback on their value allows the introduction of corrective measures. The paper aims to analyze comparatively two scientific events organized under the patronage of The Romanian Academic Society of Management. The bibliometric analysis focuses on the interdependence between the authors and the main concepts used during the two scientific events. The links between the authors and the key concepts are highlighted, while the main classifications' main reference is the Total link strength. In order to determine and better illustrate the comparative analysis, the VOSviewer program was used, a program that allows the necessary correlations between different elements specific to bibliometrics. The results obtained can help to establish measures to increase the quality and visibility of the two scientific events.
\end{abstract}

KEYWORDS: bibliometric analysis, cluster, collaboration, management, VOSviewer.

\section{DOI: 10.24818/IMC/2021/02.07}

\section{INTRODUCTION}

It is unanimously accepted that the level of development of a state is influenced (in addition to the economic, social, financial, etc. potential) by the scientific potential it has at a given time, but also its possible development in the future, in the medium or long term. Against this background, it is necessary to emphasize that the level of scientific progress cannot be quantified and, more importantly, evaluated according to the number of research institutions, the number of people involved in research and development and innovation or simply according to the level / volume of government funding in this area, the specific mechanisms in this case being much more complex and complicated.

There are many tools and techniques by which the scientific progress of a state, at national level, of a university / research institution, at organizational level or even of a person, can be evaluated objectively. Definitely, in the first phase, a quantitative evaluation will be performed, and later, based on specific indicators, a qualitative transformation will take place (in some cases, it is noted that, contextually, emphasis is placed on the quantitative evaluation of scientific research to the detriment of the qualitative evaluation, especially within universities).

The most common form by which the results of scientific research are disseminated are scientific publications, whether the traditional version on paper or the electronic, periodic or occasional format. These instruments "cumulate research results, document empirical results, provide space for theoretical debates and contribute to the gradual advancement of scientific knowledge" (Țurcan, 2019).

Although the first studies regarding the scientific literature date back to the first decades of the twentieth century (Andres, 2009), it was only in 1969 that Pritchard introduced the concept of bibliometrics, defined as "the application of mathematical and statistical methods to books and

\footnotetext{
* Corresponding author. E-mail address: manescug@yahoo.com
} 
other media of communication". As an example of good practice, it can be highlighted that on the North American continent the concept was a huge success, being used mainly by large universities. At about the same time, in Europe, Nalimov and Mulchenko (1969) introduced the concept of scientometry, defined as "the application of those quantitative methods which are dealing with the analysis of science viewed as an information process" (T,urcan, 2019). Today, when it comes to multidisciplinary and transdisciplinary research, the boundary between the two concepts has disappeared, the concepts being most often used synonymously.

From the perspective of the multitude of domains and applications of bibliometrics, Glänzel (2003) establishes a first classification of its applicability subdomains (see Figure 1).

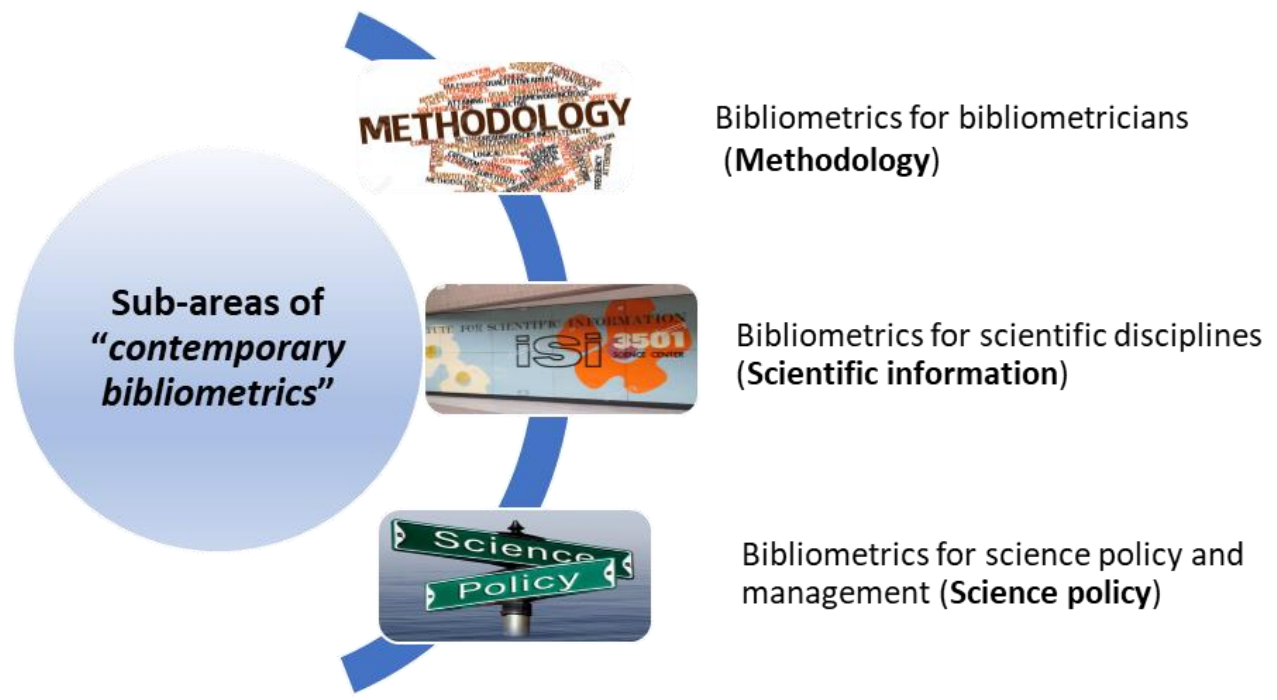

Figure 1. Sub-areas of "contemporary bibliometrics"

Source: own approach on Glänzel studies (2003, pp. 9-1).

(photo source: https://www.alamy.com/\&https://events.umich.edu/)

Subsequently, we can identify the manifestation of interdependencies between bibliometrics and other fields of activity (Glänzel, 2003) (see Figure 2).

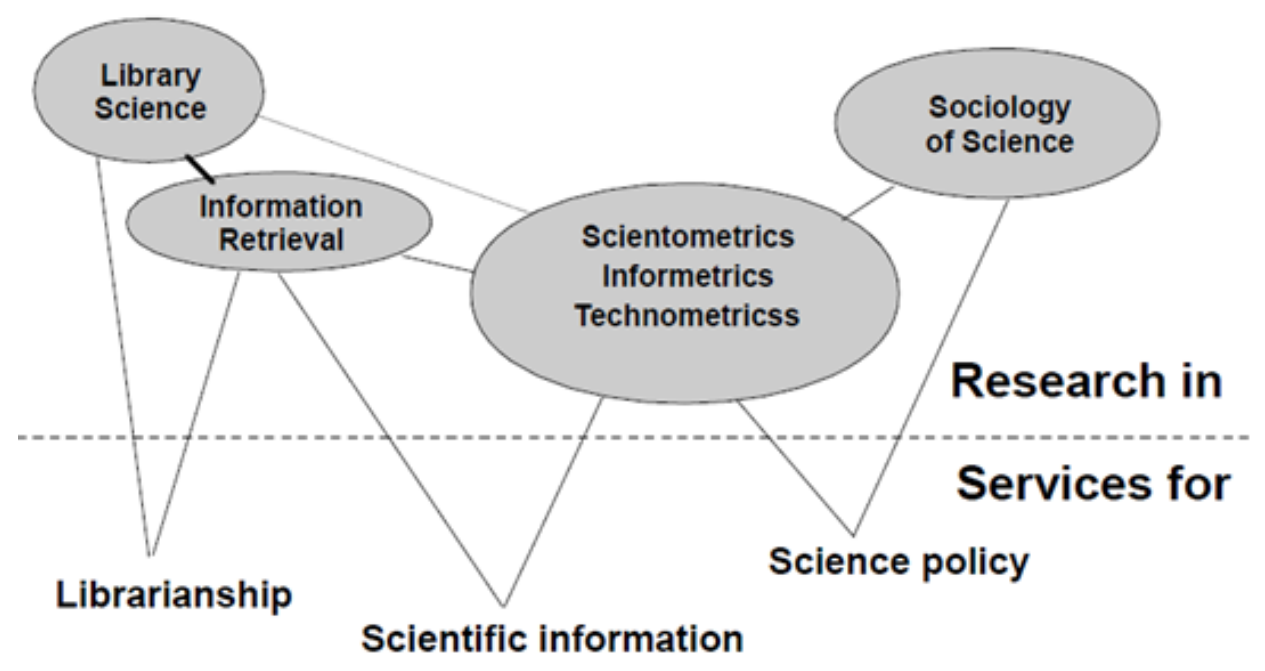

Figure 2. Links of bibliometrics with related fields and application services Source: Glänzel (2003, p. 10) 
Specifically for the field of management, sufficiently correlated in some cases with the need for own and applied research methodologies for this field, worths to be highlighted the increased amount of scientific literature produced in journals, books, websites, both academically and professionally. Some authors (Župič \& Čater, 2015) point out the role played by software programs and specialized databases, as a robust factor for increasing the relevance of these approaches, although, obviously, concerns for bibliometric analysis have existed in the past (a essential reporting here can be done using the proliferation stages of the internet and ITC means). An example of good international practice in conducting bibliometric research for management, using data provided by the Web of Science Core Collection and the VOSviewer program, is provided by Mas-Tur, A., Kraus, S., Brandtner, M. et al. (2020) with reference to the investigation in a specialized publication (The Review of Managerial Science) of the aspects regarding topics, authors, institutions, and countries, using techniques such as co-citation analysis and bibliographic coupling.

\section{METHODOLOGY}

According to Marinescu and Cicea (2018) there are two categories of bibliometric analyses:

- "bibliometric analyses which aim is to study a particular concept throughout time or its development in accordance with other specific term";

- "bibliometric analyses applied on articles published by journals or in conference proceedings".

Based on this classification, this paper aims to make a bibliographic analysis to illustrate the importance of collaboration in scientific research and especially in disseminating research results through scientific manifestations. Thus, we chose two conferences held under the high patronage of The Romanian Academic Society of Management (RASM), The International Management Conference (IMC) organized by Bucharest University of Economic Studies and The KnowledgeBased Organization (KBO) organized by "Nicolae Bălcescu" Land Forces Academy of Sibiu.

For this analysis we used VOSviewer, "a software tool for creating maps based on network data and for visualizing and exploring these maps" (Van Eck \& Walman, 2019). We examined only those editions of the conferences whose papers were indexed in Clarivate Analytics in Conference Proceedings Citation Index, namely: the IMC proceedings of the 8 editions between 2012-2019, and the KBO proceedings indexed between 2009- 2013, and the year 2015, with a total of 5 editions.

\section{RESULTS AND DISCUSSION}

\subsection{The summary of IMC \& KBO proceedings}

First of all, the data that are relevant for each of the two chosen conferences were centralized. Table 1 presents comparatively the total number of articles of the two conferences on each edition.

Table 1. Distribution of the conference papers per year

\begin{tabular}{|c|c|c|}
\cline { 2 - 3 } \multicolumn{1}{c|}{} & IMC & KBO \\
\hline 2009 & - & 370 \\
\hline 2010 & - & 323 \\
\hline 2011 & - & 379 \\
\hline 2012 & 67 & 334 \\
\hline 2013 & 52 & - \\
\hline 2014 & 88 & - \\
\hline 2015 & 69 & 153 \\
\hline 2016 & 50 & - \\
\hline 2017 & 78 & - \\
\hline 2018 & 80 & - \\
\hline 2019 & 75 & $\mathbf{1 5 5 9}$ \\
\hline TOTAL & $\mathbf{5 5 9}$ & 311,8 \\
\hline Average & 69,8 & $\mathbf{1 5 5 9}$ \\
\hline AUTORS & $\mathbf{5 5 9}$ & \\
\hline & &
\end{tabular}

Source: own research based on Web of Science (2021 a, b) 
It can be noted that, even if the KBO's papers were indexed in only 5 editions compared to 8 editions in the case of IMC, the total number of $\mathrm{KBO}$ articles is almost 3 times higher than those in IMC, the KBO conference having offered a more varied range of topics, as compared to IMC. Also, we can observe an almost uniform distribution of the number of articles published in IMC, which is almost identical in the case of the first 4 editions of KBO and which were followed by a decrease of almost 55\% in the 2015 edition (see Figure 3).

The average number of articles published at the IMC is about 70 papers / edition, a value over 4 times lower than the papers published at the KBO, which is about 312 papers / edition. The same happens in the case of the number of authors at the 2 conferences, with KBO having a number of 1559 authors, which is almost 3 times more than the IMC, which had a total number of 559 authors.

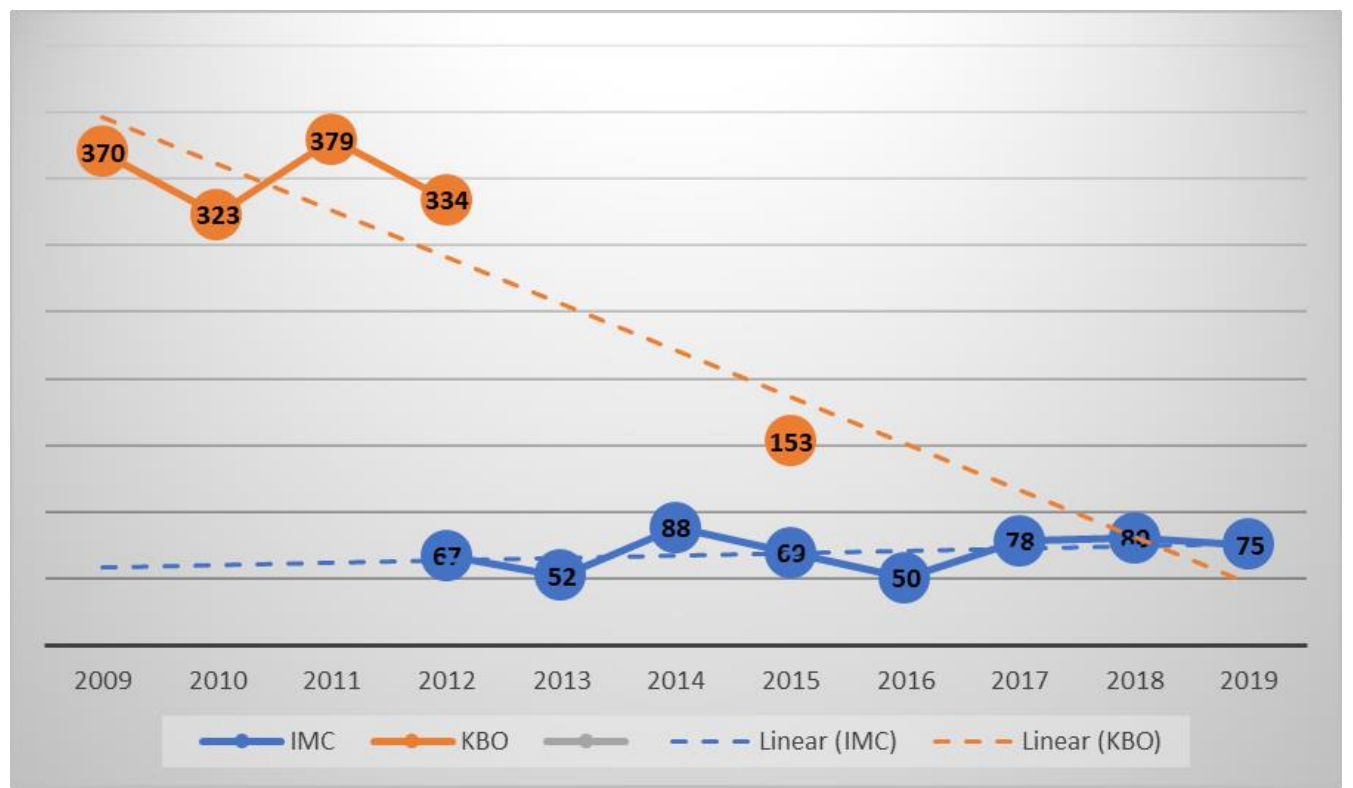

Figure 3. Yearly distribution of articles of the 2 conferences and trends Source: own research based on Web of Science (2021)

The trend is slightly increasing in the case of the IMC and decreasing in the case of the KBO. This can be explained by the fact that the non-indexation of some editions of the KBO has resulted in a reduction in the number of participants and, implicitly, in the number of articles. It is important to mention that even after 2015, the KBO proceedings were submitted for evaluation in order to be indexed, but the only answer received was that "the papers are under evaluation".

\subsection{The analysis of authorship and main items}

For this stage of our investigative approach, we used the VOSviewer software to organize and analyze the collected data. The program offers the possibility to produce maps on a lot of relevant aspects related to bibliometric analyzes. A set of maps made with this software, accompanied by related explanations, are presented in the following figures. 


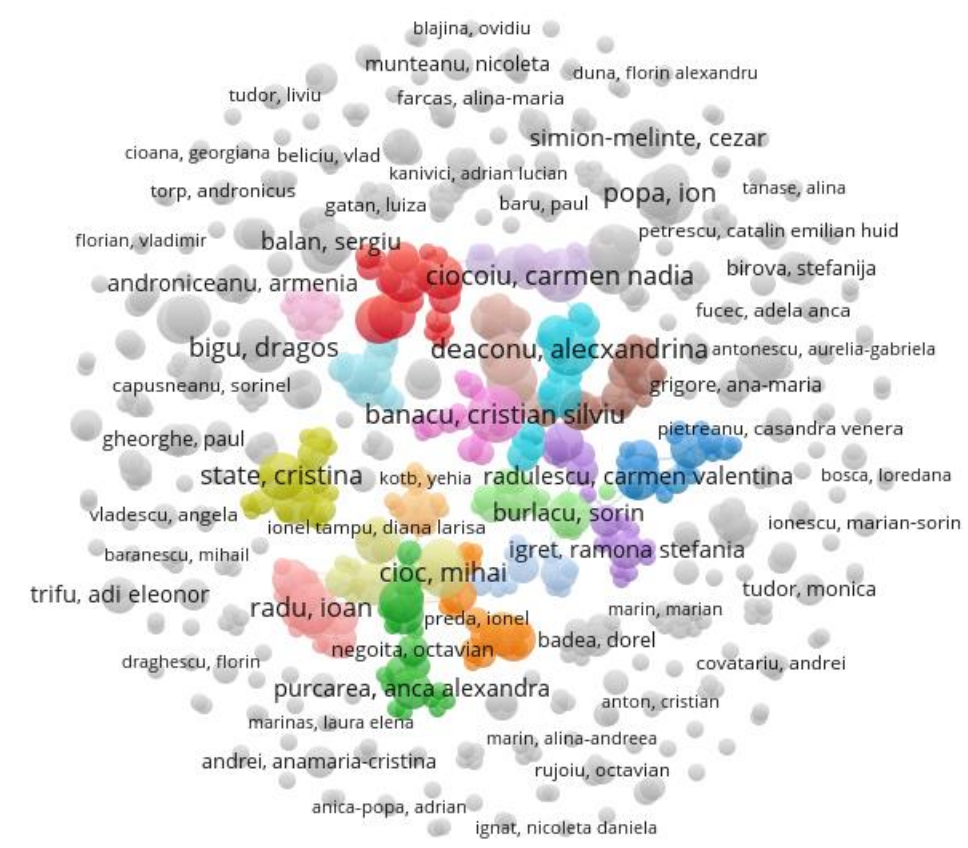

Figure 4. Map of IMC authors

Source: own research using VOSviewer software (2021)

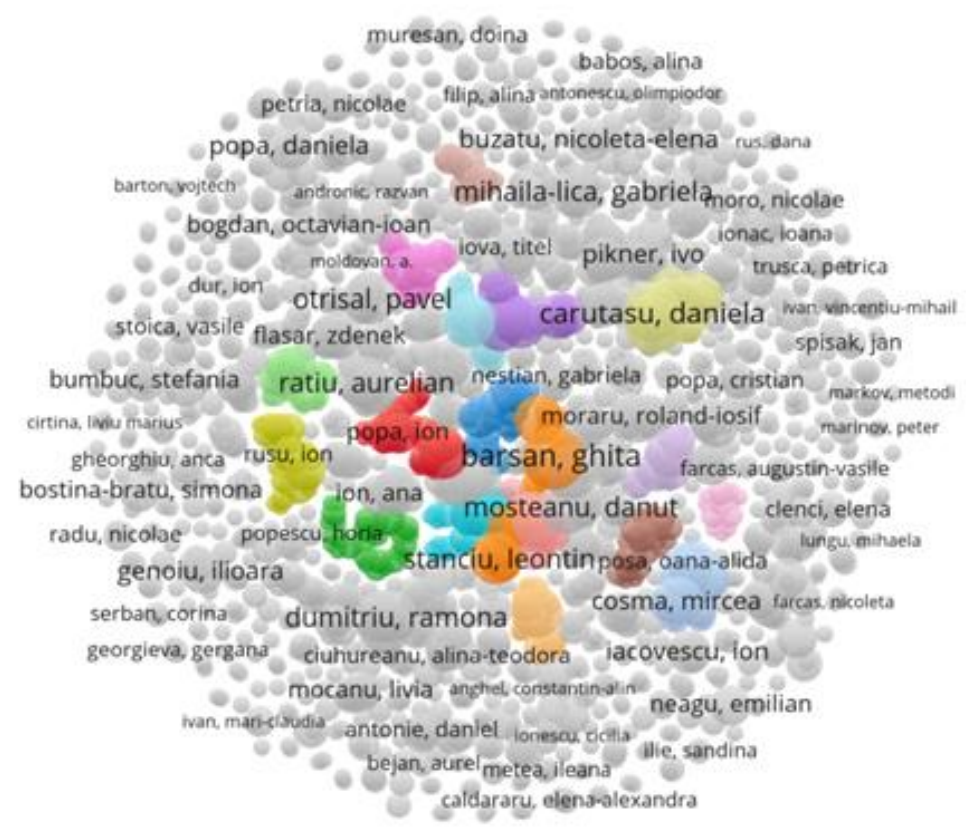

Figure 5. Map of KBO authors

Source: own research using VOSviewer software (2021)

As illustrated, the authors are grouped in clusters, which, in the interpretation of VOSviewer, are " $a$ set of items included in a map" (Van Eck \& Walman, 2019) formed around the authors, but which are also strongly influenced by the number of links between the author and co-authors, who subsequently give full power to the cluster links. Information on the total number of clusters, the number of connections and the total power of the connections established by the two events are presented in the following table: 
Table 2. Information of the bibliometric maps

\begin{tabular}{|c|c|c|c|c|c|}
\cline { 3 - 6 } \multicolumn{2}{c|}{} & Clusters & Links & $\begin{array}{c}\text { Total link } \\
\text { strength }\end{array}$ & $\begin{array}{c}\text { Total no. of } \\
\text { authors }\end{array}$ \\
\hline \multirow{2}{*}{ Initial values } & IMC & 203 & 836 & 1.003 & 559 \\
\cline { 2 - 6 } & KBO & 638 & 1.773 & 2.262 & 1.559 \\
\hline \multirow{2}{*}{ Refined values } & IMC & 24 & 384 & 468 & 216 \\
\cline { 2 - 6 } & KBO & 16 & 284 & 355 & 116 \\
\hline
\end{tabular}

Source: own research based on VOSviewer maps (2021)

The differences between the initial values and the refined values are explained by the fact that the VOSviewer program allows the identification of items that have no connection; however, for the accuracy of the analysis, these have been eliminated. Consequently, it can be seen that if, initially, the data were clearly in favor of the KBO, after the elimination of the items that are not connected, the values decrease in percentage between $25 \%$ and $47 \%$.

Based on these new values, the VOSviewer program generates the maps through highlighting the most important clusters outlined around the most important authors. As the appearance of the names of some authors can generate certain problems specific to the protection of personal data and / or those related to them, we decided not to publish these maps. Instead, we will present the top of the best author clusters (using their initials) for each scientific event (see table 3).

Table. 3. Bibliometric data of the main clusters

\begin{tabular}{|c|l|c|c|c|l|c|c|c|}
\cline { 2 - 9 } \multicolumn{1}{l|}{ Rank } & \multicolumn{4}{c|}{ IMC } & \multicolumn{4}{c|}{ KBO } \\
\hline 1 & R. I. & 8 & 12 & $\mathbf{1 9}$ & E. G. & 7 & 17 & $\begin{array}{c}\text { Total link } \\
\text { strength }\end{array}$ \\
\hline 2 & D. C. & 8 & 16 & $\mathbf{1 8}$ & B. G. & 12 & 18 & $\mathbf{2 6}$ \\
\hline 3 & B. C. I. & 10 & 15 & $\mathbf{1 7}$ & P. R. & 6 & 17 & $\mathbf{2 5}$ \\
\hline 4 & C. C. N. & 9 & 12 & $\mathbf{1 5}$ & M. D. & 9 & 16 & $\mathbf{2 1}$ \\
\hline 5 & D. A. & 9 & 10 & $\mathbf{1 4}$ & M. C. & 2 & 12 & $\mathbf{1 7}$ \\
\hline
\end{tabular}

Source: own research based on VOSviewer maps (2021)

The data in the table indicate a clear superiority over the first five clusters in favor of KBO. Also, analyzing the case of the first 3 clusters from KBO, it is very clearly illustrated that it is not the number of articles that gives the power of a cluster, but the number of collaborations.

As stated at the beginning of this study, one of the objectives is to highlight the main concepts used in the two scientific events. The main data that was at the basis of the elaboration of the maps with the main concepts are presented in table 4.

Table 4. Bibliometric data of the main concepts

\begin{tabular}{|l|c|c|}
\cline { 2 - 3 } \multicolumn{1}{c|}{} & IMC & KBO \\
\hline Total no. of concepts & 9.380 & 22,175 \\
\hline Relevant concepts & 212 & 485 \\
\hline No. of clusters & 7 & 6 \\
\hline Links & 8.956 & 26,202 \\
\hline Total link strength & 35,520 & 106,024 \\
\hline
\end{tabular}

Source: own research based on VOSviewer maps (2021)

In terms of quantity, the main elements are once more shown as clearly in favor of the KBO. One of the most important aspects is that, although the number of the most relevant concepts is over $50 \%$ 
higher in the case of the KBO, they are grouped in fewer clusters, which can be explained by their much higher occurrence, also reinforced by the Total link strength. The maps generated by the VOSviewer program for the main concepts of the two scientific events are presented in the following figures.

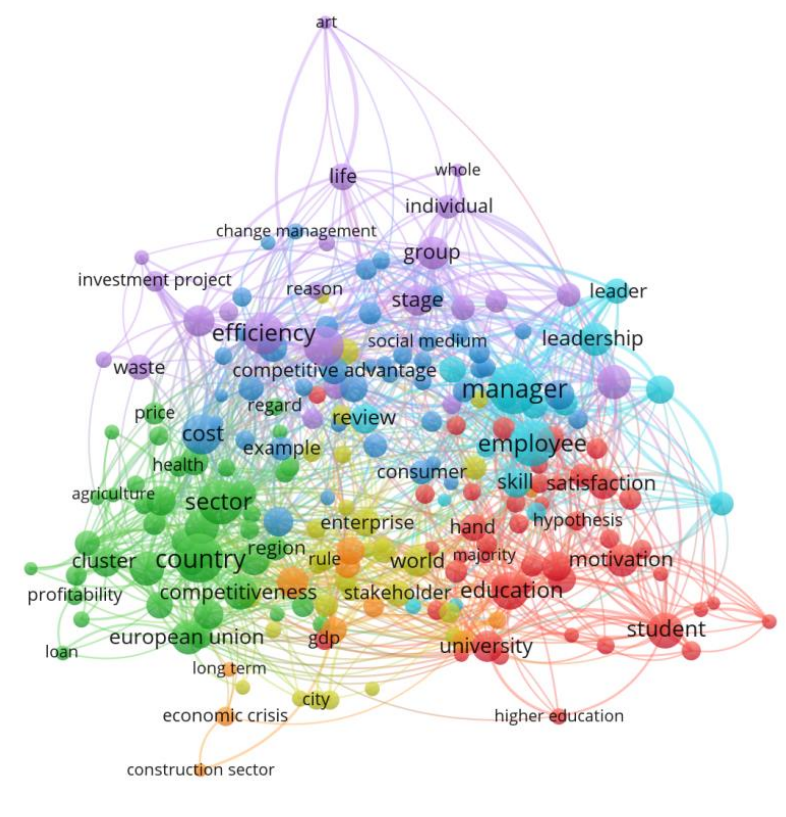

Figure 6. Map of the main concepts in IMC

Source: own research using VOSviewer software (2021)

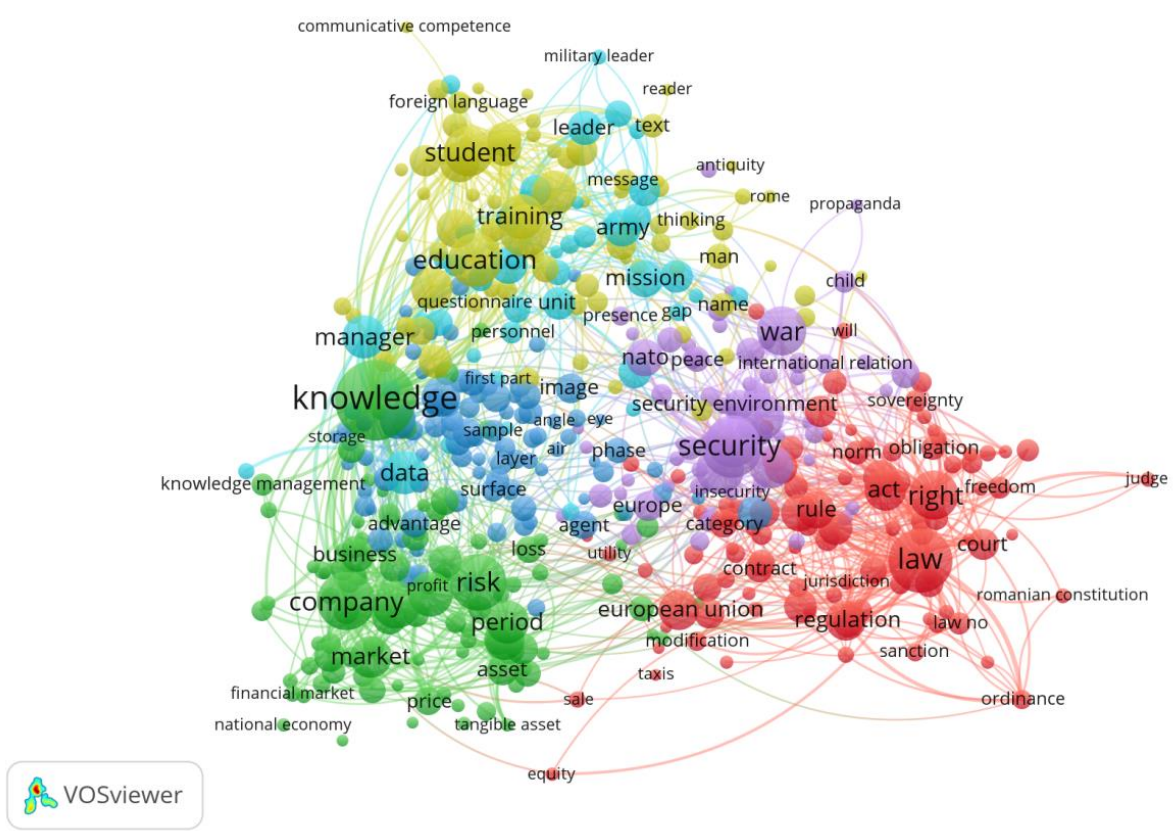

Figure 7. Map of the main concepts in KBO

Source: own research using VOSviewer software (2021)

As with the authors, the concepts are influenced by the number of links between them and Total link strength. This time, there is another factor that contributes significantly to the visibility of the 
concepts, namely the occurrence. The greater it is, the greater the importance of that concept. The following tables present the main concepts for the two scientific events analyzed, classified according to Total link strength.

Table 5. Main concepts in IMC

\begin{tabular}{|c|l|c|c|c|}
\hline Crt.no. & \multicolumn{1}{|c|}{ Concept } & Links & $\begin{array}{c}\text { Total link } \\
\text { strength }\end{array}$ & Occurrences \\
\hline 1 & Manager & 174 & 1.575 & 132 \\
\hline 2 & Efficiency & 167 & 1.442 & 85 \\
\hline 3 & Employee & 168 & 1.294 & 109 \\
\hline 4 & Country & 173 & 1.290 & 122 \\
\hline 5 & Sector & 164 & 1.167 & 99 \\
\hline 6 & Group & 135 & 1.148 & 56 \\
\hline 7 & Influence & 156 & 1.039 & 81 \\
\hline 8 & Questionnaire & 142 & 979 & 60 \\
\hline 9 & Education & 158 & 875 & 71 \\
\hline 10 & Cost & 109 & 830 & 79 \\
\hline 11 & Student & 142 & 827 & 63 \\
\hline 12 & Stage & 78 & 807 & 49 \\
\hline 13 & University & 45 & 656 & 48 \\
\hline 14 & Leadership & 651 & 54 \\
\hline 15 & Knowledge management & 223 & 23 \\
\hline
\end{tabular}

Source: own research based on VOSviewer maps (2021)

Table 6. Main concepts in KBO

\begin{tabular}{|c|l|c|c|c|}
\hline Crt.no. & \multicolumn{1}{|c|}{ Concept } & Links & $\begin{array}{c}\text { Total link } \\
\text { strength }\end{array}$ & Occurrences \\
\hline 1 & Knowledge & 358 & 4.460 & 405 \\
\hline 2 & Law & 294 & 3.831 & 254 \\
\hline 3 & Company & 271 & 2.677 & 212 \\
\hline 4 & Security & 313 & 2.534 & 228 \\
\hline 5 & Risk & 290 & 2.329 & 203 \\
\hline 6 & Student & 236 & 2.102 & 156 \\
\hline 7 & Education & 252 & 1.785 & 179 \\
\hline 8 & War & 247 & 1.785 & 150 \\
\hline 9 & Economy & 303 & 1.776 & 143 \\
\hline 10 & Protection & 259 & 1.774 & 140 \\
\hline 11 & Communication & 283 & 1.766 & 171 \\
\hline 12 & Conflict & 224 & 1.700 & 140 \\
\hline 13 & Training & 214 & 1.608 & 130 \\
\hline 14 & Language & 1.475 & 128 \\
\hline 15 & Manager & 1.334 & 117 \\
\hline
\end{tabular}

Source: own research based on VOSviewer maps (2021)

In addition to the significant differences between the descriptors of the concepts at the two conferences, which are favorable to $\mathrm{KBO}$, the concepts illustrate the specificity of the areas of expertise. It is clear that, in the case of the IMC, the concepts are mostly oriented towards the economic field, and also towards the field of education. In the case of the $\mathrm{KBO}$, most concepts are 
oriented towards the area of defense and national security but, as in the case of IMC, also towards the area of education. The concepts identical to the two conferences - which are in the first 15 concepts - clearly target the field of education, namely Student and Education.

If we analyze the first concepts used at the two conferences from the perspective of Total link strength and occurrence (see figure $8 \mathrm{a}$ and $8 \mathrm{~b}$ ), we will see a greater focus on the concept of Knowledge which is associated with specific concepts in management, education, legal, defense and national security. On the other hand, Manager, the most used concept in IMC is much more diffuse in the sense that it is mainly related to the economic field.

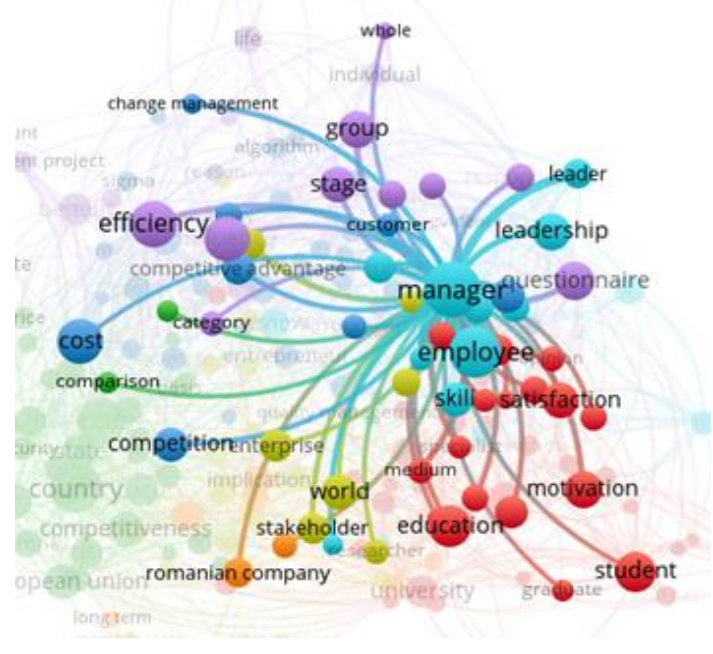

Figure 8a. Links of main concepts of IMC

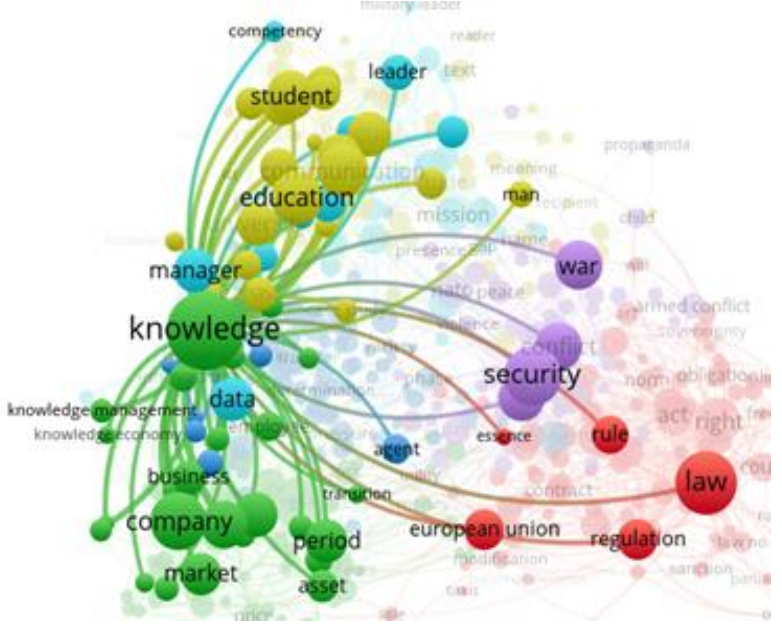

Figure 8b. Links of main concepts of KBO

Source: own research using VOSviewer software (2021)

Another aspect that we consider relevant for our study is that of citations. For this, in the VOSviewer program, we set, for the two analyzed scientific conferences, to have the authors presented and the works that are cited at least once. The program generates lists of authors who are cited with the first author as a benchmark and also considers self-citations. The number of authors and their grouping by clusters is presented in the following table.

Table 7. Number of authors cited and their grouping by clusters

\begin{tabular}{|c|c|c|c|}
\cline { 2 - 4 } \multicolumn{1}{c|}{} & $\begin{array}{c}\text { Total number of } \\
\text { authors }\end{array}$ & No. of cited authors & No. of clusters \\
\hline IMC & 559 & 119 & 119 \\
\hline KBO & 1.559 & 121 & 110 \\
\hline
\end{tabular}

It is easy to see that almost $22 \%$ of the authors in the IMC were cited compared to about $8 \%$ in the case of $\mathrm{KBO}$, but the cluster grouping shows that each author cited in the IMC is a stand-alone cluster compared to the 121 authors cited at KBO and groupings in 110 clusters, which indicates a greater relationship between authors.

Based on the data provided by the program, we made a top 5 of the most cited authors. We stopped at 5 because the number of authors cited 6 or 7 times is quite high and, in this case, the only possible hierarchy was the alphabetical one which has no relevance. 
Table 8. The most cited authors at IMC

\begin{tabular}{|c|l|c|c|c|}
\hline Crt.no. & \multicolumn{1}{|c|}{ Author } & $\begin{array}{c}\text { Year of } \\
\text { publication }\end{array}$ & No. of citation & Links \\
\hline 1 & Rădulescu, C. V. & 2018 & 37 & 0 \\
\hline 2 & Costache, G. & 2015 & 25 & 0 \\
\hline 3 & Busu, M. & 2012 & 9 & 0 \\
\hline 4 & State, C. & 2014 & 9 & 0 \\
\hline 5 & Androniceanu, A. & 2012 & 7 & 1 \\
\hline
\end{tabular}

Source: own research based on VOSviewer maps (2021)

Table 9. The most cited authors at KBO

\begin{tabular}{|c|l|c|c|c|}
\hline Crt.no. & \multicolumn{1}{|c|}{ Autor } & $\begin{array}{c}\text { Year of } \\
\text { publication }\end{array}$ & No. of citation & Links \\
\hline 1 & Cioca, L. I. & 2009 & 33 & 0 \\
\hline 2 & Moraru, R. I. & 2011 & 10 & 1 \\
\hline 3 & Moraru, R. I. & 2009 & 8 & 1 \\
\hline 4 & Moraru, R. I. & 2012 & 6 & 0 \\
\hline 5 & Luca, C. & 2011 & 6 & 0 \\
\hline
\end{tabular}

Source: own research based on VOSviewer maps (2021)

The number of citations is clear in favor of the authors from IMC but in terms of links between authors the advantage is in favor of those from KBO. As it can be seen in Table 9, the links that appear to the authors from KBO are in fact links that appear between the same author who self-cites because the articles are made in collaboration with several authors and present the results obtained at different stages of a research project.

Also, with the help of the VOSviewer program we managed to illustrate the most representative clusters made as citations of the authors at the two conferences. This was possible by setting the program parameters to split all clusters not only the most relevant ones. The most representative clusters for the two conferences are presented in figures no. 9 and 10.

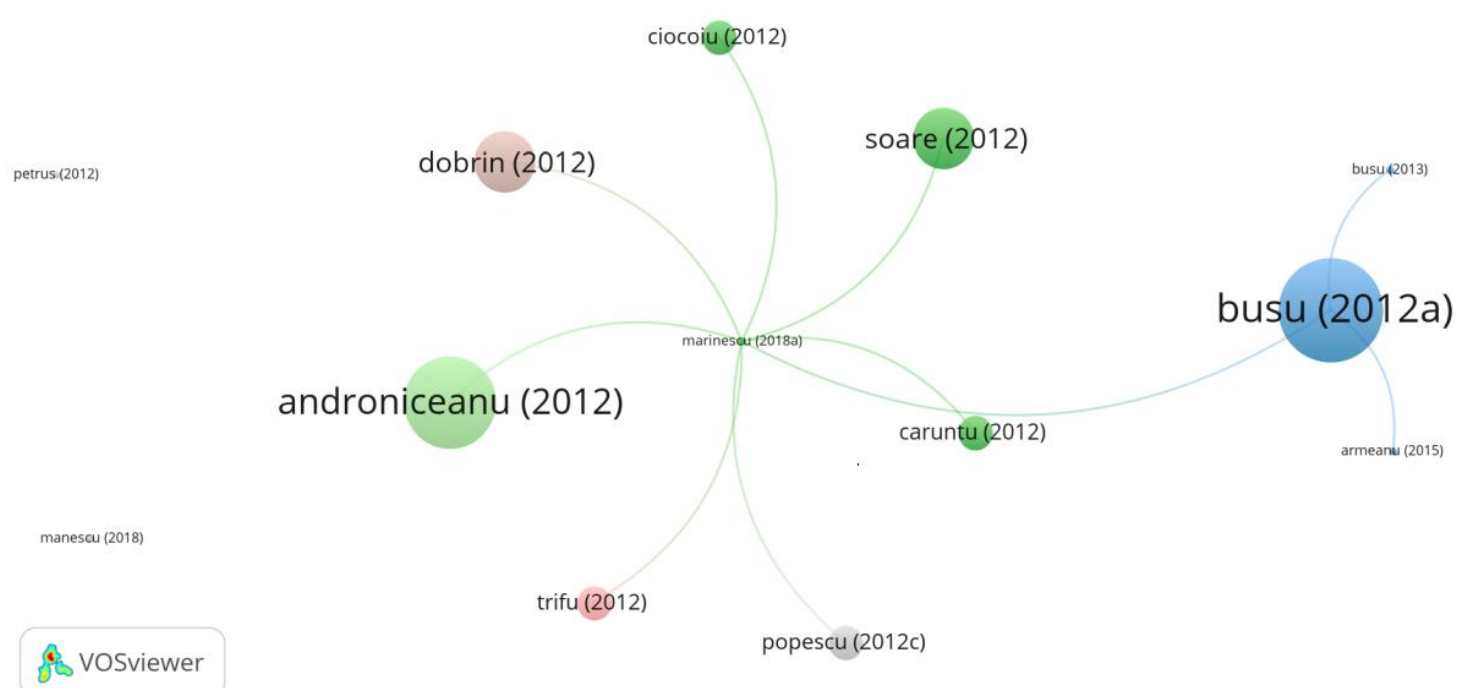

Figure 9. The main author cluster at the IMC conference

Source: own research using VOSviewer software (2021) 


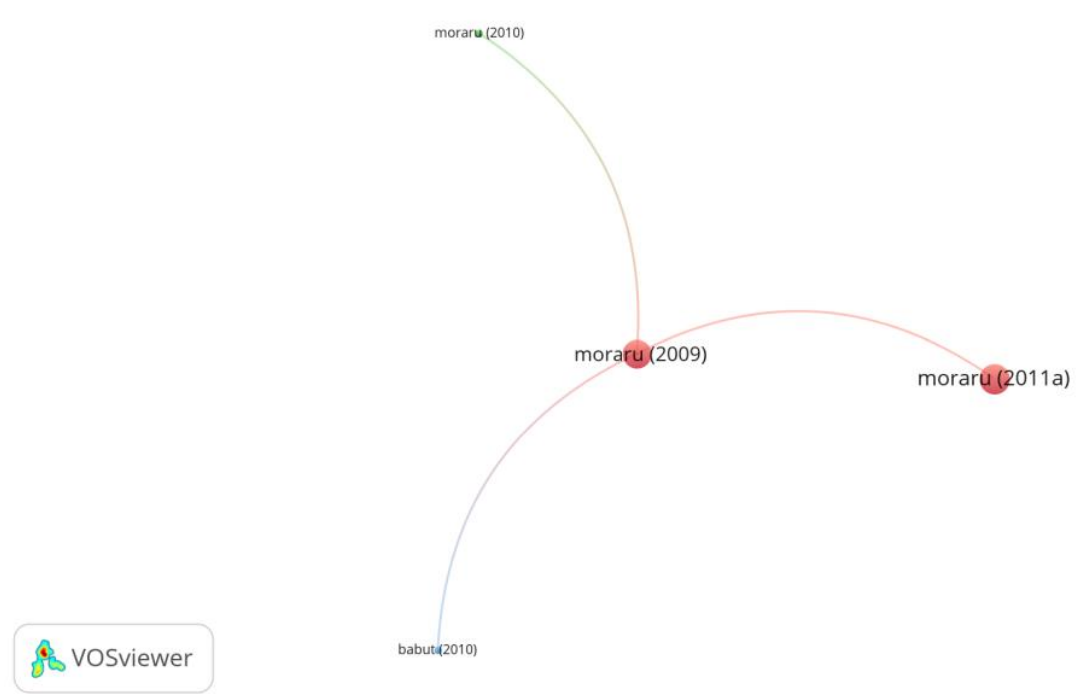

Figure 10. The main author cluster at the KBO conference

Source: own research using VOSviewer software (2021)

The IMC cluster (see figure 9) was formed around the authors Marinescu, C., \& Cicea, C. whose article entitled "A Bibliometric Analysis of the International Management Conference Proceedings' Papers" generated no less than 8 links without ever being quoted. Instead, as it can be seen in Figure 10, the KBO cluster formed around the author Moraru, R.I. whose article entitled "Knowledge based hazard analysis guidelines for operational transportation project" got no less than 8 citations and 3 links, however two of these links being with two other personal works. What is also noteworthy is the fact that the $\mathrm{KBO}$ article is appropriate for the concept of Knowledge, a concept which, as it emerged from the analysis made with the help of the VOSviewer program, is the main concept of KBO (see figure 8b).

\section{CONCLUSIONS}

The analysis conducted in this paper illustrates the power of research collaboration through the prism of bibliometric analysis of two of the scientific manifestations that have management as a central point.

The analysis showed the increasing trend of collaborations between researchers as a determining factor in the development of science. As demonstrated, even if the number of authors at a scientific event is large, this does not automatically mean that the scientific event has substance from the perspective of collaborations between authors (even if individually the balance could indicate a particular conference, this being illustrated best in tables 2 and 3). If from the perspective of collaborations between authors, the data are in favor of the IMC, in terms of the main concepts and their clustering the data are clearly in favor of the KBO. Firstly, this can be explained by the fact that niche research areas have been identified; secondly, it is due to the constancy of collaborations between authors. As illustrated in the paper, the concepts used are specific to the areas of expertise of the two institutions that organized the scientific events. This explains why concepts such as student, education, management, or knowledge, are at the forefront in terms of their use.

Even if the KBO is on a downward trend and IMC maintains its slightly upward trend, the two scientific events remain emblematic for management.

Although similar research has been conducted at national level (Pătărlăgeanu, Dinu, \& Constantin, 2020), the article's contribution to the development of research theory and practice consists in applying a specific, modern tool of analysis in the managerial field. 


\section{REFERENCES}

Andres, A. (2009). Measuring Academic Research. Oxford: Chandos Publishing. eISBN: 9781780630182.

Glänzel, W. (2003). Bibliometrics as a Research Field. A Course on Theory and Application of Bibliometric Indicators. Course handouts. Retrieved from https://bit.ly/2tpD9TN, accessed on 02.09.2021

Налимов, В. В., \& Мульченко, 3. М., Наукометрия, Изд. Наука. Москва, 1969.

Marinescu, C., \& Cicea, C. (2018). A Bibliometric Analysis of the International Management Conference Proceedings' Papers. Proceedings of the 12th International Management Conference "Management Perspectives in the Digital Era" November 1st-2nd, 2018, Bucharest, Romania.

Mas-Tur, A., Kraus, S., Brandtner, M. et al., (2020). Advances in management research: a bibliometric overview of the Review of Managerial Science. Review of Managerial Science, 14, 933-958. https://doi.org/10.1007/s11846-020-00406-z

Pătărlăgeanu, S. M., Dinu, M., \& Constantin, M. (2020). Analiză bibliometrică asupra domeniului achizițiilor publice ecologice. Amfiteatru Economic, Vol. 22, $n r$. 53, DOI: $10.24818 / \mathrm{EA} / 2020 / 53 / 71$

Pritchard, A. (1969). Statistical Bibliography or Bibliometrics?. Journal of Documentation, 24, 348-349

Țurcan, N. (2019). Fezabilitatea bibliometriei în evaluarea științei. Retrieved from https://idsi.md/fezabilitatea-bibliometriei-in-evaluarea-stiintei, accesed on 02.09.2021

Van Eck, N., \& Walman, L. (2019). VOSviewer Manual. Retrieved from https://www.vosviewer. com/documentation/Manual_VOSviewer_1.6.16.pdf, accesed on 10.03.2021

Web of Science. (2021a). Results analysis for 459 records from Web of Science Core Collection. Retrieved from http://apps.webofknowledge.com/RAMore.do?product=WOS\&search_mode= GeneralSearch\&SID=F6toNYtKNX5y3KwS7wP\&qid=2\&ra_mode=more\&ra_name=Publicati onYear\&colName $=$ WOS\&viewType $=$ raMore

Web of Science. (2021b). Results analysis for 1559 records from Web of Science Core Collection. Retrieved from http://apps.webofknowledge.com/Search.do?product=WOS\&SID=F6toNYtK NX5y3KwS7wP\&search_mode=GeneralSearch\&prID=4de4734b-732c-4b1b-bea0$6 \mathrm{dc0f9ecefd4}$

Župič, I., \& Čater, T. (2015). Bibliometric Methods in Management and Organization. Organizational Research Methods, July. https://doi.org/10.1177/1094428114562629 